\title{
Technogenic byproduct filler-based earthquake-resistant super concrete
}

\author{
M.S. Saidumov \& A.Kh. Alashkhanov \\ FSFEI HE "Millionschikov Grozny State Oil Technical University”, Grozny, Russia
}

\author{
S-A.Yu. Murtazaev \\ FSFEI HE "Millionschikov Grozny State Oil Technical University", Kh. Ibragimov Complex Institute of \\ the Russian Academy of Sciences, Grozny, Russia
}

T.S-A. Murtazaeva

Academy of Sciences of the Chechen Republic, Grozny, Russia

\begin{abstract}
The article presents an analysis of domestic and foreign experience in the production and use of high-strength concrete (HSC) and studies raw material resource base, both natural and secondary, for their production. The test results of filled binders obtained with the use of concrete scrap and brick rubble processing are given. The compositions of earthquake-resistant HSC, classified to be up to B80 in compressive strength, are obtained and the results of their tests are presented.

This work was carried out as part of research on the implementation of scientific project No. 18-48-200001 "High-quality concrete with enhanced performance properties based on local natural and secondary (processed) raw materials," which received support from the Russian Foundation for Fundamental Research (RFFR).
\end{abstract}

Keywords: High-strength concrete, super concrete, local raw materials, products of buildings and constructions demolition and dismantling, concrete scrap, brick rubble, recycling, secondary or recycled filler (sand), filled binder, concrete

\section{INTRODUCTION}

Currently, for the construction of cast-in-situ buildings and constructions, along with traditional concrete of grade B7.5-B30, new effective concrete composites are becoming widely used: highstrength, non-shrinking, expanding, straining and others, that are also made with the use of new composite or filled binders, which significantly expand the range and capacity of product units (Kaprielov et al., 2017, Bazhenov, 1995, Bazhenov et al., 2011). Specifically, according to the American Association of Cement Manufacturers, in 2012 alone, the world's leading industrial powers produced more than 13 billion cubic meters of concrete (Volkov, 2004).

It is a common knowledge that high-rise construction lead to increased demands placed on the quality of raw materials, the uniformity and stability of the compositions, the reliability and stability of the construction, etc. For concretes operating in seismically active regions, the issue of selecting the composition and designing the properties of the future composite requires even more attention. Such concretes must possess increased strength, ductility and enviable longevity (Bataev et al., 2017, Kuprina, 2014).

An analysis of scientific papers (Lesovik et al., 2012, Volodchenko et al., 2016) on highstrength concrete technology shows that their production is usually associated with the use of high-quality natural raw materials affecting the cost and increasing the energy and resource consumption of composites based on them. 
With a rational approach of using such elements as modern chemical modifiers of the concrete structure, mineral additives of various nature, as well as effective equipment for activating raw materials and homogenizing the mixture, high-strength concrete compositions based on secondary raw materials can be recommended.

First of all, concrete and reinforced concrete scrap, as well as crushed brick (rubble), which make up more than $60 \%$ of the total waste of dismantling buildings and structures, are of great interest for concrete technology (Murtazaev et al., 2009, Salamanova \& Murtazaev, 2018). According to the authors, this interest is caused by the possibility of their use as a finely ground mineral component in mixed or so-called filled binders, characterized by improved technological and physico-mechanical properties, based on which, high-strength concrete can be obtained suitable for cast-in-situ high-rise construction in seismically active regions of the country and the world.

\section{LITERATURE REVIEW}

In foreign practice, high-strength concrete (or considered to be high-strength at that time) began to appear at the beginning of the second half of the twentieth century, when concrete of classes B30 and higher began to be developed in the USA, Norway and some other countries. Later, in the 70s and 80s, analogues of modern high-strength concrete of B70-B80 compressive strength classes were known (Bazhenov et al., 2006).

Scientific works of Kim J.-K., Aitcin P.C., Skazlic M., Shi C., Talebinejad I., Strunge T., Wille K., Soutsos M., Ma J. are internationally recognised for their contribution to the development of HSC practice. Works of these researchers and of a number of other scientists, highlight the features of the technology for producing high-strength concrete and the role of mineral additives in the process of their structure formation.

According to Kim J.-K. (Kim \& Kim, 1996) and Aitcin P.C. (Aitcin, 1998) it was proved that the presence of finely dispersed fillers and additives helps to reduce the amount of portlandite and ettringite and fill capillary pores with hydration products, as a result of which a decrease in porosity and the obtainment of high concrete strength are observed.

The raw materials requirements to obtain HSC presented in the works of Aitcin P.C. (Aitcin, 1998), Skazlic M. (Skazlic \& Bjegovic, 2005) and Shi C. (Shi et al., 2015), are mainly associated with a limitation of the amount of water $(\mathrm{W} / \mathrm{C}=0.22-0.4)$, high cement content (about 450-560 kg/m3), optimization of the grain composition of aggregates (sand size modulus $\mathrm{Mk}=2.5-3$, the recommended crushed stone fraction is $10-15 \mathrm{~mm}$, the absence of flaky grains, etc.), the use of mineral fillers (finely ground additives of various nature, which reduce the porosity of cement stone), etc.

The fragility and the pattern of deterioration of high-strength concrete was investigated in the works of Richard P. and Cheyrezy M. (Richard \& Cheyrezy, 1995), where it is recommended to use fiber reinforcement in order to increase the fracture toughness of concrete. In addition, in order to obtain concrete with a strength of about $150 \mathrm{MPa}$, Cheyrezy M., Shi C. and other scientists outside of Russia suggest reducing the W/C ratio to 0.13 and argue that in this case the maximum density of the concrete composite can be achieved.

Yu.M. Bazhenov (Bazhenov, 1995), S.S. Kaprielov (Kaprielov et al., 2017), D.K.-S. Bataev (Bataev et al., 2017), V.S. Lesovik (Lesovik et al., 2012), B.C. Demyanova (Demyanova \& Gusev, 2013), V.I. Kalashnikov (Bazhenov et al., 2006), G.V. Nesvetaev (Nesvetaev et al., 2003), O.Ya. Berg (Berg et al., 2012) and others have actively contributed to the development of Russian science in the field of obtaining HSC.

Until recent times, the low demand for high-strength concrete in Russia has led to the fact that the concrete used in Russia at the end of the twentieth century secured much lower index in strength (almost 2 times) in comparison with concrete developed in the USA and Europe. The production and development of high-strength concrete in Russia is mainly associated with the development of binders of low water demand (LWD) and their modified analogues developed by Russian scientists Yu.M. Bazhenov and his students (Bazhenov et al., 2011), due to the fact that the potential for using binding ability and properties in such binders is $1.5-2.0$ 
times greater in comparison with traditional factory grinding cements. Currently, due to the development of a market economy and the development of domestic scientists in Russia, there is practically no gap in the physical, mechanical and other indicators of modern concrete used in Russia and abroad.

Kaprielov S.S., Sheinfeld A.V. and Dondukov V.G. (Kaprielov et al., 2017) studied binders for high-strength concrete and proposed optimal compositions of effective high-strength concrete for cast-in-situ construction based on the use of the MB series concrete modifier.

Works of Lesovik V.S. and his students (Lesovik et al., 2012, Volodchenko et al., 2016) develop methodological foundations for the use of energy-saving raw materials and effective technologies for the production of building composite materials, considering the genesis of the raw materials and the sustainability of the "man - material - environment" system. V.S. Lesovik is the author of a new transdisciplinary scientific field - geonics, and his scientific school solve engineering problems considering the knowledge gained during the study of natural processes and view rocks as natural analogues of building materials. Therefore, they obtained ultra-high-strength concrete using the theoretical principles of geonics and raw materials of the Kursk magnetic anomaly, which, according to the author, will be in demand in the development of the North and the Arctic, in the construction of fortifications and in the field of other anomalous conditions for the operation of materials."

Thus, the experience of researchers, both Russian and international, shows that HSC currently is and in the foreseeable future will be in great demand in the manufacture of a wide range of structural elements of civil buildings and special structures, both in earthquake-safe areas and in areas with sites for increased seismic activity (Kim \& Kim, 1996, Aitcin, 1998).

Therefore, the development of compositions of high-strength concrete based on the integrated use of secondary raw materials for their (compositions') use in concreting structural elements of high-rise cast-in-situ earthquake-resistant buildings is an urgent problem in the field of concrete technology that needs to be addressed in order to increase the efficiency of the waste recycling process resulting from dismantling buildings and structures.

\section{RESEARCH METHODS AND MATERIALS}

They are constituted by mineral fillers of technogenic nature (MFTN) for producing highquality concrete mixtures using mechanical activation and ceramic brick rubble (CBR) in a laboratory vibrating ball mill of the MV-20-EKS type to obtain a specific gravity of 450$600 \mathrm{~m}^{2} / \mathrm{kg}$. The average grinding time was $4-6$ minutes.

The chemical composition of the feedstock, as well as the macro- and microstructure of concrete samples, were studied using a Quanta 3D 200i scanning electron microscope.

The natural sand of the Chervlenskoye deposit in the Chechen Republic with the following characteristics was used as a fine aggregate: fineness modulus $\mathrm{Fm}=1.7-1.8$; the content of flour and clay particles is $1.7-1.9 \%$; void coefficient $-40.8 \%$; density $\rho_{\mathrm{s} .}=2617 \mathrm{~kg} / \mathrm{m}^{3}$; density $\rho_{\text {p. }}=1512 \mathrm{~kg} / \mathrm{m}^{3}$.

Local gravel from gravel fractions of 5-20 mm fractions of the Argun and Sernovodsky deposits of the Chechen Republic was used as a coarse aggregate.

In experimental studies, a plain Portland cement of the PC 500 D0 grade produced by the State Unitary Enterprise "Chechencement" (Chechen Republic, village of Chiri-Yurt) with normal consistency $(\mathrm{NC})=25.5 \%$, specific surface area of $3252 \mathrm{~cm}^{2} / \mathrm{g}$, water segregation (bleeding) $\leq 18 \%$ and the setting time of 2 hours and 15 minutes (start) and 3 hours 40 minutes (end) was used as a binder. The content of clinker minerals characterizing the mineralogical composition of the binder: $\mathrm{C}_{3} \mathrm{~S}=59 \% ; \mathrm{C}_{2} \mathrm{~S}=16 \% ; \mathrm{C}_{3} \mathrm{~A}=8 \% ; \mathrm{C}_{4} \mathrm{AF}=13 \%$.

Modern additives of the following manufacturers of construction chemicals were used as fluidizing agents:

1. POLYPLAST company - "Linamix PK" (liquid) superplasticizing agent (SP) and "Linamix RS" (liquid) hardening retardant based on polyoxyethylene derivatives of polymethacrylic acid; 
2. TOKAR LLC (Vladikavkaz) offers a complex multifunctional additive "D-5" (in a dry powder form) that meets the requirements of State All-Union Standard (SAUS) No. 24211-2008.

The choice between the proposed additives is due to their accessibility and cheapness, although their analogues with equal effectiveness are known in the world for instance plasticizer additives from manufacturers such as "MC-Bauchemie" ("MC-PowerFlow" hyperplasticizer based on the latest polycarboxylate ester technology MS), "Sika" company ("Sika ViscoCrete 5-600 SK" superplasticizer based on polycarboxylate esters), etc.

\section{RESULTS}

In order to obtain optimal formulations of high-strength concrete with the integrated use of the secondary raw material, compositions of filled binders (FB) with a fine-ground mineral filler of technogenic nature (MFTN - filler made of recyclables) were developed, allowing to obtain a high-strength cement stone with significantly smaller pores and less shrinkage (Table 1).

Two brands of FB with a finely ground MFTN (developed by the authors) were studied, the formulations of which are included, \% by weight:

- The brand of FB:

$\begin{array}{ll}\text { FB-75:25 } & \text { FB-60:40 } \\ 75 & 60 \\ 16 & 27 \\ 7 & 11 \\ 2 & 2\end{array}$

- PC M500 D0 «Chechencement» $75 \quad 60$

- MFTN of concrete scrap $\quad 16 \quad 27$

- Same, of CBR 7 1

- D-5 Additive 22

The compositions were developed in relation to the technology for constructing cast-in-situ bored piles of the 435-meter multi-functional high-rise complex "Akhmat Tower", erected in the city of Grozny on a site with a seismicity of 9-10 points.

Due to the fact that concrete of various strength grades (B40, B75-B80, etc.) were laid down for the design of the underground part the complex, the task of designing optimal formulations of high-strength concrete was indicated in this work, including mediumgrade concrete of compressive strength B30-B40 and high-strength - B50-B80 all of which were produced with the integrated use of secondary raw materials. At the same time, the formulations were designed to obtain highly mobile (pumpable castables) concrete mixtures with a standard cone slump of $22 \pm 2 \mathrm{~cm}$, which corresponds to the P5 workability grade, which are used in modern cast-in-situ construction field, as more efficient concrete mixtures requiring less energy for pumping through a concrete pump pipeline and subsequent vibrocompaction.

The compositions and properties of high-quality concrete mixtures with increased durability and longevity are presented in Table 2 .

Table 1. Properties of FB with fine-ground (floured) MFTN.

\begin{tabular}{|c|c|c|c|c|c|c|c|}
\hline \multirow[b]{2}{*}{ Name of a binder } & \multirow{2}{*}{$\begin{array}{l}\text { Normal } \\
\text { density } \\
\text { ND, } \%\end{array}$} & \multirow{2}{*}{$\begin{array}{l}\mathrm{S}_{\mathrm{ssa}} \text { of a }- \\
\text { binder, } \mathrm{m}^{2} / \mathrm{kg}\end{array}$} & \multirow{2}{*}{$\begin{array}{l}\text { True } \\
\text { density, } \mathrm{kg} / \mathrm{m}^{3}\end{array}$} & \multirow{2}{*}{$\begin{array}{l}\text { Water segre- } \\
\text { gation } \\
\text { (bleeding), \% }\end{array}$} & \multicolumn{2}{|c|}{$\begin{array}{l}\text { Setting time, } \\
\text { hour. - min }\end{array}$} & \multirow{2}{*}{$\begin{array}{l}\text { Activity, } \\
\text { MPa }\end{array}$} \\
\hline & & & & & Start & End & \\
\hline FB-75:25 & 17 & 558 & 2986 & 15,5 & $3-40$ & $5-30$ & 71,3 \\
\hline FB-60:40 & 19 & 577 & 2905 & 14,7 & $3-55$ & $5-35$ & 60,7 \\
\hline $\begin{array}{l}\mathrm{PC} \text { M } 500 \text { D0 SUE } \\
\text { «Chechencement» } \\
\text { (for reference) }\end{array}$ & 26 & 325 & 3115 & 18,0 & $2-15$ & $3-40$ & 52,6 \\
\hline
\end{tabular}




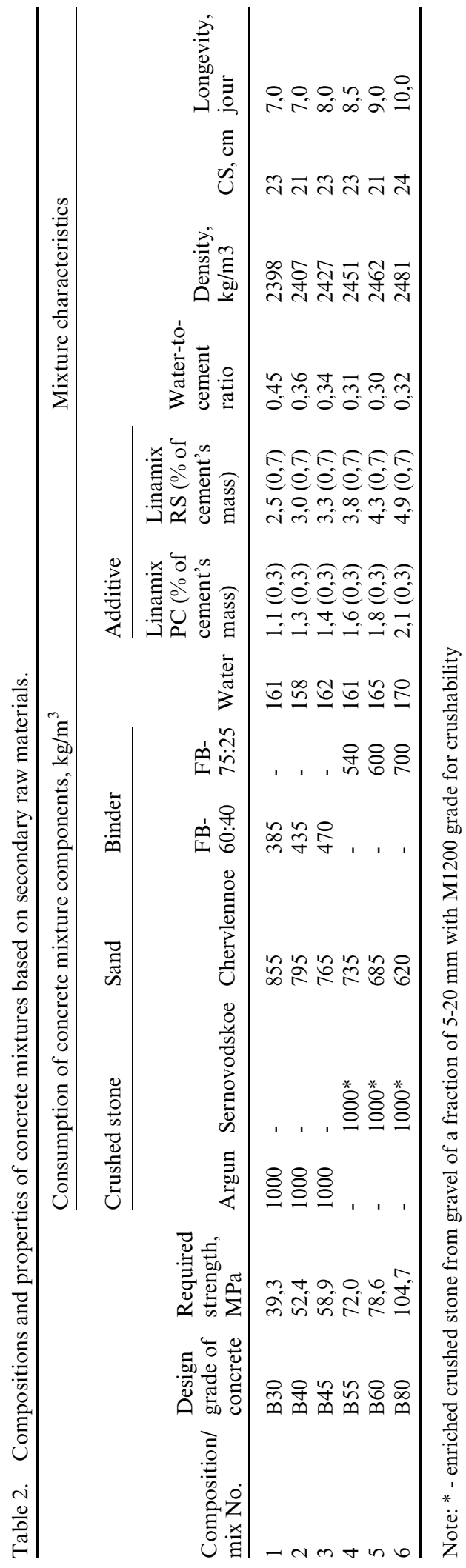


The Linamix PK superplasticizer was introduced into FB concrete mixes together with mixing water in a small amount (from 0.3 to $0.4 \%$ of the binder's weight), since the complex polyfunctional additive D-5 already has plasticizing properties in the composition of FB.

The hardening retarder "Linamix RS" was dosed in an amount of $0.7 \%$ by weight of the binder in order to ensure increased workability retaining capacity of concrete mixtures (7-8 hours or more).

The obtained experimental data on the study of the properties of HSC based on secondary raw materials of technogenic nature are presented in Table 3.

When comparing the obtained experimental results of testing concrete based on filled binders (Table 3) with known indicators of concrete strength on traditional Portland cement, you can notice the difference in the dynamics of the concrete strength gain (Figure 1).

In order to analyze the degree of homogeneity of the studied concretes based on secondary raw materials, the dependences of the prismatic strength coefficient of concretes on their compositions and on the type of binders used were studied. In addition, the proportion of the clinker part and the finely ground filler of technogenic nature in the used binders varied.

The obtained data reflecting the experimental dependencies of the prism strength $R_{P R}$ of the developed concrete using binders of various nature on their cubic strength $\mathrm{R}$, were compared with the known data of Russian scientists (Figure 2).

It was established that with an increase of the prismatic strength of concrete, its modulus of elasticity increases as well (Figure 3). Moreover, the dependence curve is slightly different from the known data obtained by prof. G.V. Nesvetaev and his students.

\section{DISCUSSION}

Based on the analysis of the results obtained, it can be stated that concretes containing filled binders that use finely ground fillers of technogenic nature are characterized by distinctive features of properties compared to traditional Portland cement concretes. In particular, this relates to retaining workability parameters of the concrete mixtures, the dynamics of curing during the first days of hardening, the strain (deformation) properties of concrete, etc. (Figures 1-3).

Therefore, the development process of FB concrete's strength characteristics at 1-3 days of age is accelerated by 1.5-2 times: on the first day FB concrete develops a strength about 33$36 \%$ higher compared to the design strength, and on the 3 -day, the strength is $65-75 \%$. Moreover, at the age of 7 days, the strength of this concrete completely exceeds $85-90 \%$ of the design strength. This differs significantly from the performance of conventional formulations that use traditional Portland cement. Thereby, these characteristics when relating to the traditional concrete at the age of 1,3 and 7 days correspond to $23-26,34-37$ and $65-70 \%$ of the design strength, respectively. Such dynamics of concrete hardening is explained by the complex effect of chemical modifiers that form the concrete as well as filled binder. Additive D-5 in concrete, which exhibits plasticizing properties during the first hours after mixing the concrete with water, begins to act as an accelerator since day one, to a certain extent. A similar effect of D-5 on the properties of concrete mix and concrete itself turn it into a multifunctional additive that positively affects both the rheological and technological characteristics of the mixture, as well as the physical-mechanical and operational characteristics of the concrete. Identically, the properties of the concrete mixes and concrete are also affected by the addition of Linamix PK, which accelerates the hardening of concrete at an early age. Such a sufficiently fast dynamics of the strength development allows you to load constructional elements at an early age (1...7 days after construction).

As is commonly known, among the most important indicators of the quality of concrete mix for cast-in-situ construction is the ability of the concrete to retain the parameters of its workability (mobility, composition stability, etc.) for a long time. In this regard, the rheological and technological properties of concrete mixtures were studied, in particular their mobility, durability, ability to retain workability, water segregation (bleeding), segregation of concrete, etc. As can be seen from Table 3, the compositions studied and proposed in this work (special concrete compositions) based on filled binders and special additives are characterized by increased capacity to retain 


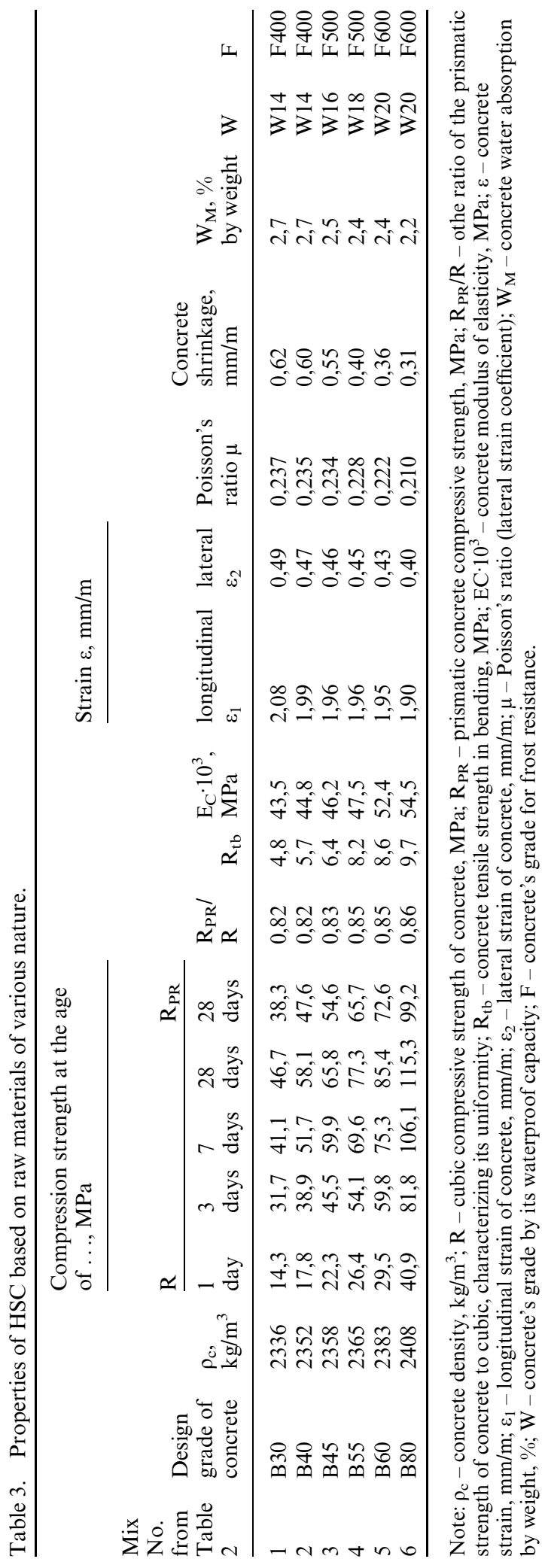




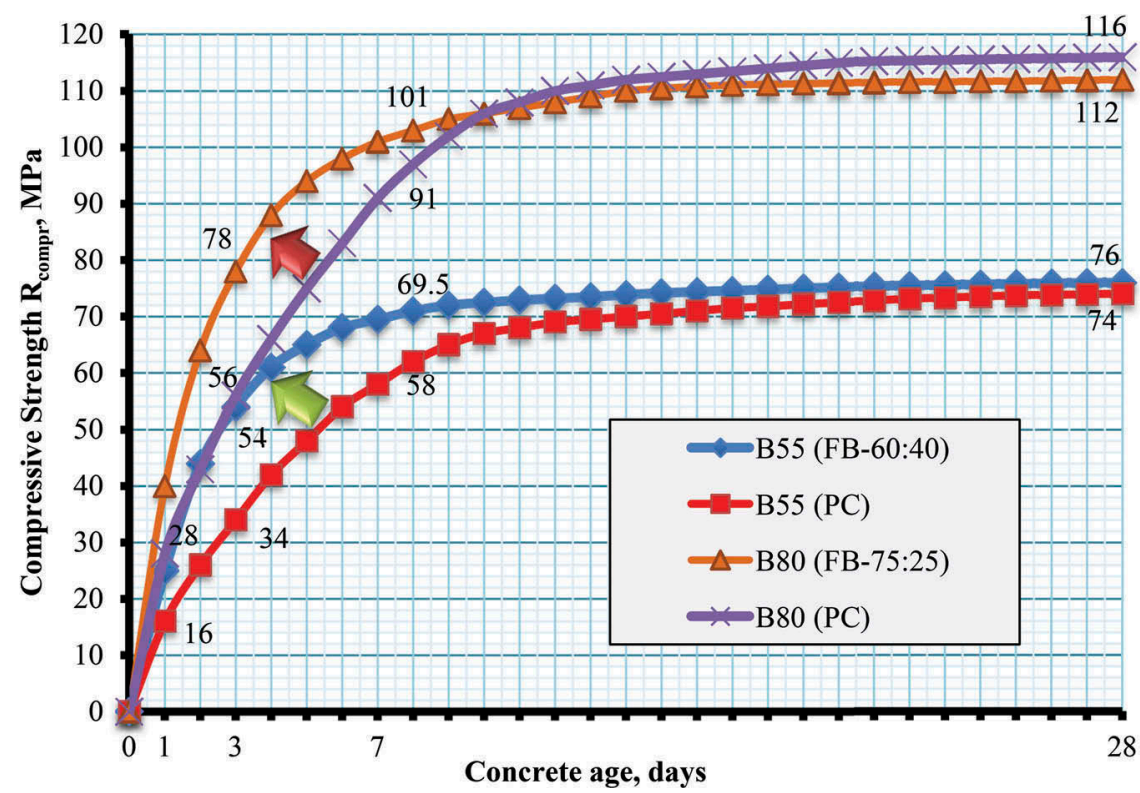

Figure 1. Assessment of the concrete strength characteristics growth (over time), depending on the type of binder.

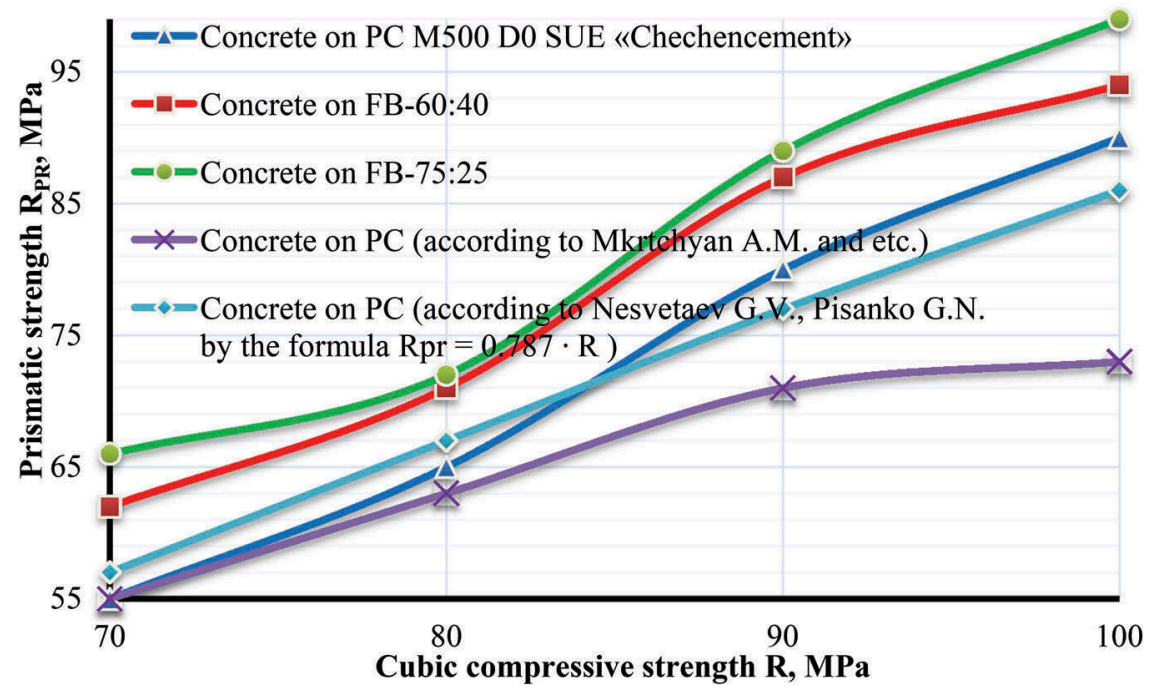

Figure 2. Dependence of the prism strength $\mathrm{R}_{\mathrm{PR}}$ on cubic $\mathrm{R}$ when using binders of various nature.

workability (8-10 hours). High rates of workability parameters preservation of concrete mixtures contribute to the production of an integral in-situ construction without the formation of "cold joints" in case of unforeseen circumstances associated with breakdown of equipment and tools, failure to supply the mixture, etc. And after the end of the inhibitory effect of the additive, these mixtures quickly gain strength at an early age (1-3 days), which increases the efficiency of form reuses and, as a result, drastically reduces the construction time, which is very important in modern cast-in-situ construction. For elements of the precast reinforced construction industry, 


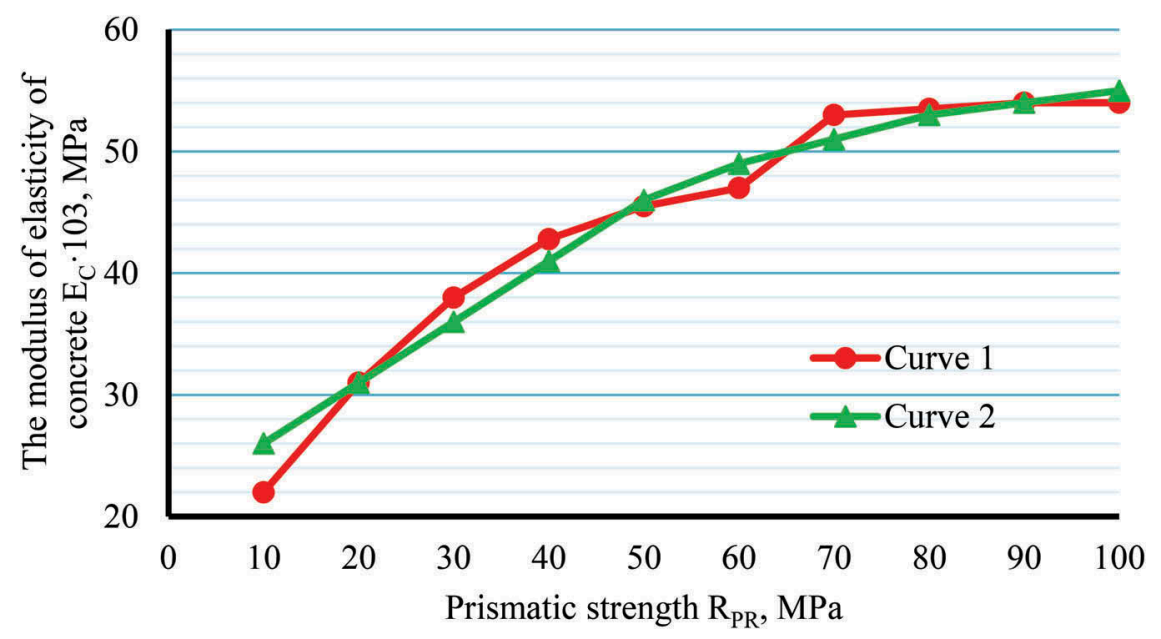

Figure 3. Dependence of the elastic modulus of HSC produced with a finely ground MFTN (curve 1) and ordinary concrete (curve 2, according to G.V. Nesvetaev) on its prism strength.

such a feature of the proposed concrete formulations (high durability, rapid strength development, etc.) will slash the manufacturing time of constructions, and in some cases, partially or completely eliminate the cost of concrete steaming.

\section{CONCLUSIONS}

Formulations of filled binders (FB) with an activity of 60-71 MPa with finely dispersed mineral fillers of technogenic origin (MFTO), including concrete scrap and ceramic brick (CBK) with a ratio of $70: 30 \%$, respectively, were developed and studied, with the proportion of the filler mixture in FB amounted to 25 and $40 \%$ by weight of the binder.

Using secondary raw materials, optimal formulations of concrete mixtures with a grade of P5 in cone slump along with its capacity to retain workability for more than 8 hours were designed to produce HSC.

The physical-mechanical characteristics of HSC made of secondary raw materials of B60B80 grades were studied, and the development of their strength characteristics over a period of time depending on the type of binder was evaluated. It was found that the process of strength development of FB concrete is accelerated by 1.5-2 times at an early age (1-3 days). So, FB concrete at the age of 1 day has a strength of about $33-36 \%$ of the design, and at the age of 3 days - it reaches up to $70 \%$. The 7-day strength of concrete obtained using FB is about $85-90 \%$ of the design, which is significantly higher than the performance of traditional "PortlandCement" (PC) compositions.

It is proved that the prismatic strength coefficient (i.e., the RPR/R ratio) for FB concrete is in the range of $0.82-0.86$, whereas the traditional PC concrete shows only 0.78 or lower.

The stress-related (deformational) properties of HSC based on secondary raw materials were studied. It was found that the concrete modulus of elasticity of the proposed compositions of HSC, prepared on the basis of secondary raw materials, is in the range of $40,2 \times 10^{3}-$ $54,5 \times 10^{3} \mathrm{MPa}$, depending on the strength of concrete and the type of filler. Moreover, the higher the strength of concrete, the higher its modulus of elasticity.

It is experimentally proved that the ultimate longitudinal $\varepsilon_{1}$ and lateral $\varepsilon_{2}$ strains of the HSC on finely dispersed MFTN are $1.93-2.32 \mathrm{~mm} / \mathrm{m}$ and $0.41-0.66 \mathrm{~mm} / \mathrm{m}$, respectively. For straight cement concrete of traditional composition, they usually reach $\varepsilon_{1}=3.2-3.6 \mathrm{~mm} / \mathrm{m}$ and $\varepsilon_{2}=1.9-2.0 \mathrm{~mm} / \mathrm{m}$. It is discovered that with an increasing concrete strength and higher proportion of finely ground MFTN the longitudinal and lateral strains decrease. 
It was found that the Poisson's ratio $\mu$ (lateral strain coefficient) for HSC with a finely ground MFTN is in the range of 0.21-0.285. It was found that with an increase in concrete strength, the Poisson's ratio of HSC decreases, which indicates a more fragile nature of the structure of such concrete with an increase in their compressive strength grade.

Thus, the given deformation characteristics of the developed HSC testify to their high resistance to dynamic influences, including seismic ones.

It has been proved that HSC based on FB with fine-ground MFTN are characterized by high grades in frost resistance (F300-F500) and waterproof (W14 and higher), demonstrating a solid evidence of high durability and longevity of such concrete.

\section{REFERENCES}

Aitcin, P.C. 1998. High-performance concrete. London: E\&FN SPON.

Bazhenov, Yu.M. 2011. Fine-grained concrete from recycled materials for the repair and restoration of damaged buildings and structures: scientific publication / Yu.M. Bazhenov, D.K.-S. Bataev, St. A.Yu. Murtazaev, H.N. Mazhiev. - Grozny: IE "Sultanbegova H.S.".

Bazhenov, Yu.M. 1995. Concrete of the 21st Century/Yu.M. Bazhenov // Resource- and energy-saving technologies of building materials, products and structures: Sat. scientific tr Int. conf. -Belgorod.

Bazhenov, Yu.M. 2006. Modified high-quality concrete: scientific publication / Yu.M. Bazhenov, B.C. Demyanova, V.I. Kalashnikov. - M.: Publishing house of the Association of construction universities.

Bataev, D.K.-S. 2017. Recipes of high-strength concrete based on technogenic and natural raw materials / D.K-S. Bataev, M.S. Saydumov, T.S.-A. Murtazaeva, D.M. Dudaev, M.K. Salgiriev // Actual problems of modern building science and education: materials of the All-Russian scientific-practical conference dedicated to the 60th anniversary of the building faculty of FSBEI HE "GSTU named after Acad. M.D. Millionschikova", October 12-13, 2017 - Grozny: P. Bisultanova.

Berg, O.Ya. 2012. High-strength concrete/O.Ya. Berg, E.N. Shcherbakov, G.N. Pysanko. -M.: Stroyizdat.

Demyanova, V.S. 2013. Effective building materials using industrial waste/V.S. Demyanova, A.D. Gusev. -Penza: PGUAS.

Kaprielov, S. S., Scheinfeld, A. V., Dondukov, V. G. 2017. Cements and additives for the production of high-strength concrete // Building materials. - No. 11.

Kim, J.-K., Kim, Y.-Y. 1996. Experimental study of the fatigue behavior of high strength concrete // Cement and Concrete Research. -Vol. 26, -Issue 10.

Kuprina, A.A., Lesovik, V.S., Zagorodnyk, L.H., Elistratkin, M.Y. 2014. Anisotropy of materials properties of natural and man-triggered origin // Research Journal of Applied Sciences. -Vol. 9.- Issue 11.

Lesovik, B.C. 2012. Building composites based on screenings for crushing concrete scrap and rocks: scientific publication/B.C. Lesovik, St. A.Yu. Murtazaev, M.S. Saydumov. -Grozny: Municipal Unitary Enterprise "Printing House".

Murtazaev, S-A.Yu. 2009. Fine-grained concrete based on fillers from recycled materials [Text]: scientific publication / S-A.YU. Murtazaev, D.K.-S. Bataev, Z.K. Ismailov, Kh.N. Mazhiev, St. M.K. Khubaev. -M.: Komtekhprint.

Nesvetaev, G.V. 2003. Evaluation of the effectiveness of superplasticizers for high-strength and high-quality concrete / G.V. Nesvetaev, A.V. Nalimova, G.V. Bumblebee // Proceedings of universities. Construction, -№ 9.

Richard, P., Cheyrezy, M. 1995. Composition of reactive powder concretes // Cement and Concrete Research. -No. 25.

Salamanova, M.Sh. 2018. Clinker-free binders based on finely dispersed mineral components/Murtazaev S.A. Yu., Salamanova M.Sh. // Collected: ibausil conference proceedings. - -FROM. 707-714.

Shi, C., Wu, Z., Xiao, J., Wang, D., Huang, Z., Fang, Z. 2015. A review on ultra high performance concrete: Part 1. Raw materials and mixture design // Construction and Building Materials. -No. 101.

Skazlic, M., Bjegovic, D. 2005. Perspectives of designing with new concrete types. Zagreb: Annual 2005 of the Croatian Academy of Engineering.

Volkov, Yu. 2004. Concrete basis for modern skyscrapers / Yu. Volkov, A. Zvezdov // Construction. - No. 5.

Volodchenko, A.A., Lesovik, V.S., Zagorodnjuk, L.H., Volodchenko, A.N., Aleksandrovna, K.A. 2016. The control of building composite structure formation through the use of multifunctional modifiers // Research Journal of Applied Sciences -№ 10 (12). 